\title{
Soot Formation in Diffusion Oxygen-Enhanced Biodiesel Flames
} Wilson Merchan-Merchan*, Stephen McCollam, Juan Felipe Correa Pugliese School of Aerospace and Mechanical Engineering, University of Oklahoma, Norman, OK 73019, USA

\section{Abstract}

The focus of this work is the experimental investigation of soot formation in coflow flames formed of two fatty acid methyl esters (FAMEs) by employing the light extinction/scattering technique. Three different sets of experiments were conducted in this study. In the first set, radial soot volume fraction $\left(f_{\mathrm{v}}\right)$ profiles of flames of vaporized neat canola methyl ester (B100CME) and neat soy methyl ester (B100SME) fuels both using air as the oxidizer were obtained. In the second set of experiments, the effect of oxygen content in the oxidizer stream on soot formation was studied in both FAME formed flames by increasing the oxygen content in the oxidizer stream from $21 \%$ to $35 \%, 50 \%$ and $80 \%$. In the third set of experiments, the effect of fuel blending on the formation of soot particulates was studied in flames formed using CME blended with No.2 diesel. The blends consisted of $80 \%$ biodiesel and 20\% diesel (B80), and 50/50\% (B50) biodiesel/diesel. The flames were scanned in the radial direction at various heights above the burner $(\mathrm{HAB})$. For the $\mathrm{B} 100 \mathrm{CME}$-air flame the measured soot volume fraction $f_{\mathrm{v}}$ peak was $4.04 \mathrm{ppm}$ and was located at the symmetry axis at a HAB of $16.25 \mathrm{~mm}$. For B100SME-air, the $f_{\mathrm{v}}$ peak was measured to be $4.22 \mathrm{ppm}$ at approximately the same flame height as in the CME-air flame. For the B100CME oxygen enriched-air flames the peak values at 35\%, 50\% and $80 \%$ were $6.50,5.82$ and $3.22 \mathrm{ppm}$, respectively. It was observed that by increasing the oxygen content in the B100CME flame from $21 \%$ to $35 \%$ oxygen, the $f_{\mathrm{v}}$ peak increases by approximately 61 percent. However, a further increase in oxygen content in the oxidizer stream suppressed soot formation. A similar trend in the $f_{\mathrm{v}}$ was observed for B100SME oxygenenhanced flames. Furthermore, the increase of diesel fuel in the blending of B50CME resulted in significantly higher $f_{\mathrm{v}}$ values compared to the B80CME. The addition of oxygen content in the oxidizer stream in these blended fuel flames (from air to $35 \%$ ) resulted in an increase in the $f_{\mathrm{v}}$ peak of approximately 47 and 71 percent, respectively. Centerline temperatures were measured at various $\mathrm{HAB}$ for selected flames.

Keywords: Soot formation, Biodiesel, Carbon particulates 
* Corresponding Author: E-Mail: wmerchan-merchan@ou.edu; Phone: Phone number:

$32+1+405-325-1754$

\section{Introduction}

Biodiesel (BD) has the potential to significantly address environmental concerns by reducing greenhouse gas emissions, interrupt the dependence on petroleum-based fuels and tremendously contribute to the local economy. A biodiesel fuel (BDF) which can be prepared

37 from vegetable oils and animal fats is considered a clean, biodegradable and renewable fuel and alkyl esters of long-chain (C16-C18) fatty acids, usually methyl esters, obtained by the transesterification of the triglycerides contained in vegetable oils and animal fats [1]. Today, petroleum-based fuels meet $36 \%$ of U.S. energy demand [2] with 70 percent directed to fuels used in transportation including gasoline, diesel and jet fuel. Diesel fuel is predominantly used by light to heavy-duty trucks [3] and due to its high aromatics content, it is responsible for massive particulate matter emissions in the flue gases, which in turn trigger major health and 45 environmental issues. The application of $\mathrm{BD}$ and biodiesel/diesel blends in diesel engines has 46 been shown to be not only feasible, but also favorable in terms of lubricity and most-regulated 47 pollutant emissions [4]. Due to the great potential of BDF in the transportation industry [5], some studies have reported on the measurement and characterization of particulate matter and gaseous 49 emissions collected from the exhaust flows in internal combustion engines and gas turbines [6,7]. 50 In recent years, BD research efforts has been focused on the synthesis processes, type of 51 catalyst, and performance of this alternative fuel [8-12]. Numerous studies have been conducted 52 on the thermo [13,14], catalytic pyrolysis [15-17], and heat of combustion, and these properties 53 have also been studied by varying the blending percentages of BDF with petroleum-based fuel 54 [18]. 
The present experimental study is aimed at understanding the soot formation in controlled

56 coflow laminar diffusion flames formed using two fatty acid methyl esters including: B100CME

57 (100\% Canola Methyl Ester), B100SME (100\% Soybean Methyl Ester), fuel blending includes

$58 \mathrm{~B} 50$ and B80. The fuel blending ratio (BD/ No.2 ULSD) is indicated by a " $\mathrm{B}$ " with a subsequent

59 number. The number following the " $\mathrm{B}$ " represents the percentage of BD in the mixture, for

60 instance B100CME represents a 100 percent canola methyl ester or neat BD. The effect of soot

61 formation is also studied in these oxygenated fuels by increasing the oxygen content in the

62 oxidizer stream from air to $35 \%, 50 \%$ and $80 \%$. The study is conducted using a nonintrusive

63 laser extinction technique. In the present study canola and soybean biodiesels were used mainly

64 due to their large scale availability, and therefore the impact they can have as alternatives to

65 petroleum-based fuels. Canola and soybean oils have lower level of saturated fats compared to

66 other vegetable oils resulting in a BD with very low Cloud Point (CP) which allows the methyl

67 esters to perform better than other BDF at lower temperatures [19]. The CP for CME and SME

68 is $0^{\circ} \mathrm{C}$ and $1^{\circ} \mathrm{C}$, respectively [19]. The $\mathrm{CP}$ is defined as the temperature that allows small, solid

69 crystals to form in a fuel as it is cooled. Oil generated from canola feedstocks is considered an

70 excellent lubricant in engines operating under extreme heat and steam conditions [20, 21]. The

71 oil adheres to metal surfaces better than any other oils generated from other feedstocks. The

72 production rate of a certain type of a BDF is largely a factor of the ability to produce its

73 feedstock at a large scale. Canada is the largest producer of canola seed producing 7 million tons

74 each year [20]. In 2008 it was reported that Canada produced 1.6 million tons annually of canola

75 oil $[22,23]$. The United States and Brazil are the major producers of soybeans in the world. The

76 total production of BD in the U.S. in June 2014 was 100 million gallons [24]. A total of 822 
77 million pounds of feedstocks were used to produce BD in the U.S. alone in the month of June

782014 with soybean oil ranking as the largest biodiesel feedstock with 467 million pounds [24].

79 Studies of engines running with diesel fuel and soybean oil BD comparing the performance and emissions at certain engine running conditions have been performed by Canakci et al. [25]. In

81 that study it was shown that $\mathrm{CO}$ emissions were $18 \%$ lower for neat soybean BD compared to

82 neat petroleum-based diesel. In the same study it was shown that the concentration of NOx

83 emissions is reported to increase in the flue gas by $12 \%$ when running with a soybean BD (due to

84 the content of oxygen in the $\mathrm{BD}$ ) compared to the neat petroleum-based diesel. The particulate matter (PM) from neat soy and canola BD is also shown to be significantly reduced in size nanostructure from a light-duty diesel engine running with various blending ratios of fuel

89 (ULSD/SME) was reported by Vander Val et al. [27]. Through high resolution transmission electron microscopy that work aimed to study the physical presence of soot nanostructure as 91 fullerenic shells and/or graphitic lamellae correlated to BD blend ratio. Studies using diesel engines can provide useful information such as structural 93 characteristics of the particulate matter and gaseous species emitted from diesel engines collected 94 from the exhaust subsequent to the combustion process. However, the products in the exhaust normally undergo a dilution process of clean dry air. Dilution ratio and residence time in the

97 compositions that are different. However, fundamental studies directly inside a controllable 98 laminar diffusion flame can suppress some of the physical variables that are encountered in such 99 complex combustors, allowing for a better understanding of the fuel and its characteristic 
combustion properties. Until recently only very few fundamental studies on the thermal and pollutant emissions have been conducted on BD formed flames [28-32] and on droplet BD combustion [33]. The study of soot formation and other pollutant emissions resulting from BD flames is a nearly unexplored area.

During the last decade new and improved oxygen generation technologies are making the application of oxygen-enhanced combustion (OEC) and or oxy/fuel combustion more affordable and attractive [34]. It is stablished in the literature that OEC can increase performance in a combustion process. In a typical combustion process (using air as the oxidant) the presence of soot increases the radiant heat transfer efficiency properties which can be significantly further improved by OEC [34]. Over the last decade, OEC and oxy-fuel combustion have been successfully incorporated into a variety of industrial processes, including glass furnaces, boilers, and incinerators [34]. It is known that burning hydrocarbons (liquid fuels/natural gas) with oxygen-enriched air significantly improves the thermal efficiency of the process by increasing the temperature of the flame, flame stability, in addition to a massive reduction in the flue gas volume [34]. Another advantage of OEC addresses the continual increase in the emphasis on the environment. A combustion process with a higher percentage of oxygen can significantly reduce the amount of NOx formed. Given the feasibility of oxygen for increasing (effect on soot and temperature in flame) radiant heat transfer and hence the performance of a combustion process, it is imperative to study and understand the soot particle formation in oxygen and oxygen-enriched air flames formed using these new emerging and alternative form of energy (biodiesel fuel).

\section{Experimental setup and procedures}

Figure 1 contains the overall experimental setup used in this study including the coflow burner, liquid fuel injection and pre-vaporizer, laser extinction approach and BD flames characteristics. 
123 The coflow burner employed in this study is a slightly modified version of the one originally

124 developed for soot volume fraction measurements in methane/ethane flames by Santoro et al.

125 [35]. The co-annular burner is placed on a two-dimensional, step motor driven positioner (Fig.

126 1a). For laser extinction measurements a computerized control - data acquisition system scans

127 the soot distribution of the flame in radial directions at various positions height above the burner

128 (HAB). The burner consists of two concentric tubes of $11 \mathrm{~mm}$ and $82 \mathrm{~mm}$ in diameter, with the 129 vaporized fuel flowing through the central tube, and the oxidizer supplied to the lower section of 130 the burner by four axially symmetric inlet ducts flowing through the outer channel (Fig. 1b). The 131 oxidizer duct has inner and outer diameters of $12.7 \mathrm{~mm}$ and $82 \mathrm{~mm}$. The oxidizer stream with 132 oxygen content varied from $21 \%$ to $80 \%$ was prepared by mixing flows of industrial bottled 133 oxygen (98\% Airgas) and laboratory dry air. A flow rate of $36 \mathrm{lpm}$ is used for the oxidizer. A 3$134 \mathrm{~mm}$ diameter glass bead bed and a honeycomb disk are used to evenly distribute the oxidizer 135 flows inside the burner. The oxidizer flow is initially introduced into a vacant chamber in the 136 bottom section of the burner separated by a stainless steel mesh. The mesh retains a bed of $3 \mathrm{~mm}$ 137 diameter glass beads further distributing the flow. Finally, a $51 \mathrm{~mm}$ thick ceramic honeycomb 138 section $(1.5 \mathrm{~mm}$ cell size) is used directly above the glass beads to establish stable uniform 139 oxidizer flow. For oxygen-enhanced combustion the flows (air/O2) are initially introduced into a 140 vacant chamber containing glass beads to completely mix the flows before they are introduced 141 into the burner. Figure 1c contains representative photographs of coflow flames formed using 142 B100CME at various oxygen content in the oxidizer stream from $21 \%$ to $80 \%$. Figure 1d 143 contains characteristics of flames formed at B80CME, B50CME and B100SME. Additionally, a 144 more complete set of photographs of the flames studied herein is presented in Supplementary 145 Data-1. Liquid BD is pumped into a pre-vaporization chamber, Fig. 1a. The chamber is 
146 externally heated and fully insulated; the inner temperature can be continuously monitored and

147 maintained at the desired temperature to evaporate the liquid fuel. A heated and insulated line 148 connects the outlet of the pre-vaporizer with the burner. The liquid BD is supplied at a constant 149 rate of $6 \mathrm{ml} /$ hour employing a syringe pump (Model EW-74900-00 1-Channel from Cole150 Parmer, Inc.). The wall of the fuel evaporator assembly and fuel line were successively heated 151 by an array of three heating tapes set to 350,475 , and $500^{\circ} \mathrm{C}$. The temperature settings were 152 accomplished using temperature controllers. The liquid BD was introduced into the pre153 vaporization chamber set at $350^{\circ} \mathrm{C}$. The other two heating tapes set at higher temperatures were 154 placed downstream in the fuel line connecting the outlet of the prevaporizer with the burner to 155 prevent condensation of the vaporized fuel. High temperatures for vaporizing a liquid fuel can 156 induce cracking and polymerization reactions, causing significant changes in the chemical 157 composition and therefore in the soot propensity of the fuel. The biodiesel's thermal stability in 158 this study was ensured by maintaining the vaporized fuel temperature lower than $275^{\circ} \mathrm{C}$ as 159 suggested by Lin et al. [36]. In our experiments this effect was verified by measuring the 160 temperature of the gas flow at the fuel nozzle in the burner. Moreover, visual inspection of 161 unburned fuel extracted from the fuel line showed no carbonization or visual indication of severe 162 fuel cracking during the vaporization process. The low volatility of a BDF can cause difficulties 163 for flame ignition and sustainability, thus, in order to stabilize the flame it was necessary to 164 introduce a small $(<0.1 \mathrm{lpm})$ nitrogen flow as a carrier gas into the fuel line. The heating tape 165 wrapping the wall of the pipe carrying the flow of nitrogen was set to $400^{\circ} \mathrm{C}$. The oxidizer line 166 was also preheated to $200^{\circ} \mathrm{C}$ (wall temperature). Liquid fuels such as No. 2 diesel and BD 167 (CME and SME) employed in this study are composed of a variety of constituents (Table 1 and 168 2). BDF is principally composed of unsaturated fatty acids while diesel is composed mainly of 
saturated hydrocarbons (no double bonds) and aromatic compounds (ringed structures containing

170

171

172

173 (Paraffins, monocycloparaffins, bicycloparaffins, and tricycloparaffins) and aromatic

174 hydrocarbons (alkylbenzenes, teralins, dinaphthenobenzenes, naphthalenes, acenaphthenes, 175

6 carbons and alternating single and double bonds). For instance, SME is composed of methyl palmitate (13\%), methyl stearate (5\%), methyl oleate (25.0\%), Methyl linoleate (52\%) and methyl linolenate (5\%) by weight (Table 1). No. 2 diesel is composed of saturated hydrocarbons acenaphthylenes, and phenanthrenes). Diesel fuel average percent composition by volume is shown in Table 2. Compared to diesel fuel, BD have higher cetane numbers, contain approximately $11 \%$ oxygen by weight, and lack aromatic compounds [37]. Flame temperature measurements of selected flames were also carried out in this study. All temperatures were taken using fast-response K-type thermocouples (Omega Engineering, Inc) made of bare chromega and alomega. The K-type thermocouple had a bead diameter of $0.7-\mathrm{mm}$ with the exposed junction. The rapid insertion technique was used [38,39]. The thermocouples were mounted on a traversing insertion mechanism and connected to a data acquisition board.

\section{Soot volume fraction measurements}

The laser extinction/scattering method is an attractive optical technique that allows for nonintrusive and instantaneous measurement of soot volume fractions $\left(f_{\mathrm{v}}\right)$ within the flame volume and has been widely employed in the combustion community. In previous studies of laminar diffusion flames, tomographic reconstruction has been proven useful in providing spatially resolved measurements of $f_{\mathrm{v}}$ based on line-of-sight extinction measurements [40-42].

For soot particles in the Rayleigh size limit (particle diameter/light wavelength $<<1$ ) (Bockhorn, 1994) [43] $f_{\mathrm{v}}$ averaged along the line-of-sight was calculated using the following expression: 


$$
\frac{I}{I_{0}}=\exp \left(-\frac{K_{E X T} L f_{V}}{\lambda}\right)
$$

191 From this relation $f_{\mathrm{v}}$ is obtained as:

$$
f_{v}=\frac{\lambda \ln \left(\frac{I_{o}}{I}\right)}{K_{E X T} L}
$$

192 Where, $L$ is the path length, $I_{0}$ is the incident laser intensity, $I$ is the transmitted laser intensity, $f_{\mathrm{v}}$ 193 is the soot volume fraction, and $K_{\text {ext }}$ is the extinction coefficient. The $K_{\text {ext }}$ is obtained from the 194 refractive index of soot. Many measurements of the refractive index of soot have been reported 195 during the last decades $[44,45]$. Some studies in this particular area have reported that refractive 196 indices may be independent of fuel [46] others have shown that a refractive index can be a 197 function of flame position and $\mathrm{C} / \mathrm{O}$ ratio [46, 47]. In the present study the soot measurements 198 employed an extinction coefficient of 4.9 that corresponds to the refraction index, $\mathrm{m}=1.57-0.56 \mathrm{i}$ 199 (Dalzell and Saforim, 1969) [48].

200 In order to scan the soot profiles, the coflow burner was mounted on a two-dimensional, stepping 201 motor positioning system. A personal computer data acquisition system was used to control the 202 operation of the positioning system and to conduct the light extinction measurements. Laser 203 beam extinction experiments were performed using a compact stabilized HeNe laser (Model 204 HRS015 from Thorlabs Inc.). The resulting output power at $632.99 \mathrm{~nm}$ was $<5 \mathrm{~mW}$ with long205 term drift less than $0.3 \%$ in 8 hours. The stabilized laser beam is focused into the flame and 206 deflected back using two $50.8 \mathrm{~mm}$ diameter lenses (Newport Inc.) equally spaced to provide 
207

208

209

210

211

212 without a flame.

213 The reactor is run by a computer program to perform repetitive sampling at pre-specified

214 locations defined in terms of the dimensions of the scanning area and the step size. After each

215 step, the data acquisition system takes measurements at the current location for a pre-specified

216 period of time, averages them and saves already preprocessed data, before moving to the next

217 scanning point. The "experimental errors" in our measurements of the soot volume fraction were

218 minimized by obtaining soot volume fraction profiles of an ethylene-air flame. The precision of

219 the laser extinction setup was validated using the results available in the literature for that

222

223

224

225

226

227 The present experimental study is aimed at understanding the soot formation process in 228 controlled coflow laminar diffusion flames formed using two FAMEs (B100CME and 229 B100SME), fuel blends including B50CME (mixture of 50\% BD and 50\% No.2 diesel) and particular flame. The intensity of the transmitted light (I/Io) after the laser beam passed through the flame at different radial positions was measured. The transmittance was measured for various flame heights. Soot volume fractions where then obtained by using the collected transmittance. The transmitted light and soot volume fractions at the two flame positions correlate well to published values in the literature $[35,49]$. The field distribution function was obtained using a three-point Abel deconvolution algorithm [50].

\section{Results and Discussion}


B80CME (mixture of $80 \% \mathrm{BD}$ and $20 \%$ No.2 diesel) by employing the light extinction/scattering technique. The effect of soot formation is also studied in the mentioned fuels by increasing the oxygen content in the oxidizer stream from air to $35 \%, 50 \%$ and $80 \%$. Soot volume fraction profiles for all flames were acquired using the nonintrusive laser extinction technique. Centerline temperature measurements were also conducted for selected flames along the symmetry axis of the flames at different HAB using a thin-tip fast-response thermocouple, by means of the rapid insertion technique $[38,51]$.

4.1 Soot volume fraction measurements in flames formed using B100CME and B100SME, with air and oxygen-enriched air as oxidizers

Soot volume fraction $\left(f_{\mathrm{v}}\right)$ measurements using the laser extinction technique were first conducted with neat BDF formed from canola and soybean oils (B100CME and B100SME). Figures $2 \mathrm{a}$ and $3 \mathrm{a}$ contain soot volume fraction profiles along the radial direction of the flame at various HAB for B100CME-air and B100SME-air flames. Similarly, figures 2(b, c, d) and 3(b, c ,d) present profiles of soot volume fraction for B100CME and B100SME oxygen-enhanced flames. Inspection of figures 2 and 3 show that all curves display similar $f_{\mathrm{v}}$ evolution along the axial direction over the entire flame. Soot is first detected at the lower zone of the flame near the fuel-oxidizer interface forming a "wing" like structure, overlapping the luminous envelope of the flame where the highest temperatures in the radial direction are expected. The double wing-like profiles characteristic of the lower zone develop into a single peak distribution in the mid zone of the flame, which continue shrinking in the axial direction and eventually vanish for all radial locations near the tip of the flame. For the B100CME-air flame (Fig. 2a), the soot volume fraction peak was measured as $4.04 \mathrm{ppm}$ and was located at the symmetry axis at approximately $\mathrm{HAB}=16.25 \mathrm{~mm}$. For B100SME-air (Fig. 3a), the $f_{\mathrm{v}}$ peak was found to be $4.22 \mathrm{ppm}$ located also 
253 on the symmetry axis at approximately $\mathrm{HAB}=18.75 \mathrm{~mm}$. It is interesting to note that the peak

254 soot volume fractions for B100CME and B100SME do not vary significantly. In the literature

255 it is shown that flame temperature variations could impact the soot particle inception limits [52].

256 A work of Gomez et al. studied the effects of fuel-type and temperature on soot formation along

257 the centerline of axisymmetric laminar diffusion flames [53]. In that work it was suggested that

258 the soot formation process is highly temperature dependent. Figure 7a and (b) represent

259 measured temperature profiles along the centerline axial direction of a B100CME and

260 B100SME, respectively. A comparison between the two flame temperature profiles reveals that

261 the general trends and values are nearly the same. The flame temperature variations between the

262 B100CME-air and B100SME-air are not very significant and may explain a similarity in the

263 mechanisms of soot formation between these two fuels. The temperature profiles are also similar

264 for the BD oxygen enriched-air flames. Furthermore, studies on soot formation reported by Love

265 et al. [30] showed that soot volume fractions obtained in vaporized B100SME and B100CME

266 premixed flames do not significantly vary between the two fuels compared to that of the

267 petroleum-based fuel (diesel). In that study it was reported that the $f_{\mathrm{v}}$ peak for the B100SME-air

268 is approximately $1.15 \mathrm{ppm}(\mathrm{HAB}=10 \mathrm{~cm})$ and the $f_{\mathrm{v}}$ peak for B100CME has a value of $1.3 \mathrm{ppm}$

$269(\mathrm{HAB}=5 \mathrm{~cm})$. In the same study it was shown that the formed premixed flame temperature

270 peaks between these two fuels do no significantly vary. For the B100CME a highest temperature

271 of $1850 \mathrm{~K}(\mathrm{HAB}=5 \mathrm{~cm})$ was reported. For the B100 SME the highest temperature was $1820 \mathrm{~K}$

272 and occurred at $\mathrm{HAB}=10 \mathrm{~cm}$. Soot inception can also be affected by a mechanism other than

273 flame temperature such as fuel chemistry. The content of constituents in a fatty acid methyl ester

274 varies according to the feedstock employed and can significantly affect the physical, chemical,

275 and fuel properties [54]. In the present study both CME and SME are composed of methyl 
276

277

278

279

280

281

282

283

284

285

286

287

288

289

290

291

292

293

294

295

296

297

298

palmitate, methyl stearate, methyl oleate, Methyl linoleate and methyl linolenate (Table-1). On the other hand, animal fats (AF) contain methyl myristate, methyl palmitoleate, methyl heptadecanoate in addition to all of the constituents present in the CME and SME.

However, the $f_{\mathrm{v}}$ peak value for B100CME-air flame is approximately 11 times higher than the $f_{\mathrm{v}}$ peak reported by K.O. Lee et al.[42] for a $\mathrm{CH}_{4}$-air flame using the same burner configuration. And approximately a $f_{\mathrm{v}}$ peak value that is approximately 13 times higher for a B50CME-air flame. It is well established in the literature that combustion of heavier hydrocarbon compounds such as diesel fuels has a tendency to produce high quantities of soot compared to lighter hydrocarbon fuels such as methane. The work of Kitamaura et al. showed that the beta-scission reaction plays an important role in the degradation pathway of the fuel molecules in the diesel [55]. Such reactions are responsible for generating a higher density of PAH species and as a result, significantly increasing the availability of precursors for soot inception and soot formation in a flame medium. This effect is quite visible in our soot measurements. On the other hand, the $f_{\mathrm{v}}$ peak for B100CME-air flame is approximately 2.5 times smaller than the peak value reported by Tran [56] for pure ultra-low sulfur diesel in a wick generated flame of similar dimensions. In comparison to No. 2 diesel fuel, the absence of aromatic compounds in CME and SME is believed to be the reason for the lower particulate matter emissions. The tendency of a BDF to form less sooty flames, opposed to a diesel fuel, can also be attributed to the nature of the fuel itself (hydrocarbon oxygenated compounds). Kitamura et al. proposed a detailed reaction mechanism for studying the effect of the oxygen molecule (bounded in the long chain fatty acids esters) and how it affects soot tendency [55]. It was suggest that the oxygen molecules present in the ester tend to remain bounded to the nearest carbon atom in the carbon chain promoting the formation of ketones and aldehydes. These 
species are highly resistant to oxidation and are only oxidized by powerful oxidizing agents which have the ability to break the bonds. Soot studies by McEnally et al. by doping small concentrations of aldehydes and ketones in a coflow $\mathrm{CH}_{4} / \mathrm{N}_{2}$ nonpremixed flame showed that the carbonyl group tend to reduce the soot tendency of the overall flame [57]. The plots in Fig. 2(bd) show the $f_{\mathrm{v}}$ peak values for B100CME at $35 \%, 50 \%$ and $80 \%$ oxygen as $6.50 \mathrm{ppm}, 5.82 \mathrm{ppm}$ and $3.22 \mathrm{ppm}$, respectively. Similarly, figure $3(\mathrm{~b}-\mathrm{d})$ shows the $f_{\mathrm{v}}$ peak values for B100SME at $35 \%, 50 \%$ and $80 \%$ oxygen as $4.94 \mathrm{ppm}, 4.4 \mathrm{ppm}$ and $3.25 \mathrm{ppm}$. It is observed that by increasing the oxygen content in the B100CME flame from $21 \%$ to $35 \%$ the $f_{\mathrm{v}}$ peak increases by approximately 61 percent. However, the further increase of oxygen content in this type of flame yields significantly reduced $f_{\mathrm{v}}$ peak values. That is, for B100CME using $50 \%$ and $80 \%$ oxygen in the oxidizer stream results in $f_{\mathrm{v}}$ peak value reductions of 10 and 44 percent, respectively. The further increase of oxygen content in the oxidizer stream significantly suppresses soot formation. The effect of oxygen content suppressing soot formation is also visible for the B100SME based flame but not as strong as the B100CME based flame (Fig. 3).

The introduction of oxygen enrichment in the oxidizer stream to form the coflow diffusion flame significantly modifies the physical and thermal properties of the flame. As the oxygen content is increased, the flame volume is compressed and the overall flame temperature is increased. The strong variation of the physical structure of the flame as the oxygen enrichment is increased is obvious from our soot volume fraction and temperature profiles. Inflame axial temperatures were measured at different locations along the symmetry axis of the flame upstream from the fuel nozzle. Figure 7 shows typical flame temperature profiles for B100CME and B100SME flames operated at $21 \%, 50 \%$ and $80 \%$ oxygen content in the oxidizer stream. The temperature measured in-flame by the thermocouple bead is exposed to heat losses caused by radiation, conduction 
and convection. Recognizing that different investigators use different methods and procedures for the correction of thermocouple measured temperatures; profiles of temperatures formed using the raw readings "uncorrected values" are presented. A simplified yet well accepted approach was employed for correcting thermocouple measurement errors. A more complete approach requires proper values for the various heat transfer properties and velocity of the flame gases. In this approach the Nusselt number correlation for obtaining the convection heat transfer coefficient is based on a non-reacting flow. Hindasageri et al. employed a unique transient technique for accurately determining the heat transfer coefficient in premixed methane-air flames without the use of thermophysical properties and velocity of gases [58]. It was reported that the heat transfer coefficients can have an average deviation of $20 \%$ from the available heat transfer correlations present in the literature for cylinders and spheres exposed to non-reactive convective flows. However, temperature profiles formed using "corrected" values are incorporated as supplementary data (Supplementary Data-2). The general trends for the temperature profiles "uncorrected" vs. "corrected" are very similar. To correct thermocouple measured flame temperatures the method proposed by Jha et al. was employed [31]. Corrections can be estimated by using an energy balance equation on the thermocouple bead [31]. For the axial velocity an analytical expression proposed by Roper et al. [59] was employed. In that expression the constant acceleration value of $25 \mathrm{~m} / \mathrm{s}^{2}$ due to buoyancy for a controlled laminar diffusion hydrocarbon/air flame was employed similar to the work of Zelepouga et al. [41]. It is worth noting that since the studied flames are laminar there is little effect on the change of the value of the corrected flame temperatures by varying the axial gas velocity even by several folds. The axial centerline flame temperature (for both B100CME and B100SME) increased sharply just above the edge of the burner's mouth right after the fuel nozzle exit (Fig. 7). The recorded flame temperatures near the burner's mouth were $480^{\circ} \mathrm{C}(\mathrm{CME}-$ air $), 560^{\circ} \mathrm{C}\left(\mathrm{CME}-50 \% \mathrm{O}_{2}+50 \% \mathrm{~N}_{2}\right)$ and $780^{\circ} \mathrm{C}\left(\mathrm{CME}-80 \% \mathrm{O}_{2}+20 \% \mathrm{~N}_{2}\right)$, 
346

347

348

349

350

351

352

353

354

355

356

357

358

359

360

361

362

363

364

365

366

367

368

Fig.7(a). The flame tested with the highest oxygen content $\left(\mathrm{CME}-80 \% \mathrm{O}_{2}+20 \% \mathrm{~N}_{2}\right)$ contains the strongest temperature gradient. The centerline flame temperature for that particular flame varies from $\sim 780^{\circ} \mathrm{C}$ just above the burner's mouth to $\sim 1150^{\circ} \mathrm{C}$ near the flame's tip. The total flame height for the $\mathrm{CME}-80 \% \mathrm{O}_{2}+20 \% \mathrm{~N}_{2}$ is less than $10 \mathrm{~mm}$ indicating that soot inception, growth and oxidation mechanisms are much stronger under oxygen-enriched conditions. These results show that oxygen enrichment in the oxidizer stream can significantly (up to a certain point) alter the flame temperature and as a result increase the rates of fuel pyrolysis. The increase of the rate of fuel pyrolysis can strongly contribute to the augmentation in the formation of soot precursors (soot inception) in the lower part of the flame and consequently yield flames with high soot volume fraction peak. A brief examination of the soot volume fraction profiles compared to those of the measured local flame temperatures at each flame height reveals that the higher the temperatures, the higher the oxidation rate of the soot particles. This trend confirms that the addition of oxygen in the oxidizer stream of the coflow diffusion flames alters the flame reaction zone yielding essential variations in soot concentration. A quite similar trend was also found in our previous works for traditional fuels [34]. However, the further increase of oxygen content in the oxygen/nitrogen mixture formed flame in our experiments appears to suppress soot formation. It has been shown that the introduction of diluted fuel in the fuel line and/or oxygenenriched air in the oxidizer stream can strongly influence the flame flow fields (reduction in flame volume) and significantly reduce soot formation in flames. The work of Sugiyama suggested that soot yield reduction in a laminar coflow nonpremixed flame is attributable to the changes in the flame velocity and flame shape [60]. Furthermore, from our soot volume fraction profiles (figures 2 to 6 ) it can be observed that the further increase of oxygen in the oxidizer stream (above 35\%) significantly suppressed soot formation. Furthermore, the trends of our soot 
369

370

371

372

373

374

375

376

377

378

379

380

381

382

383

384

385

386

387

388

389

390

391

volume fraction profiles are in line with the findings reported by $\mathrm{Du}$ and Axelbaum that soot inception can be dramatically affected by flame structure through changes in fuel pyrolysis and oxidation rates adjacent to the pyrolysis zone [61]. In our present study it is observed that the overall soot formation effect for oxygen enhanced flames is a trade-off between the augmented fuel pyrolysis rates resulting from higher flame temperatures, and the reduced residence time of the soot within the flame due to the shrinkage of the reacting zone. In the work of Li et al. a visual comparison of the appearance of the flame structure "flame streak" of a burning droplet stream showed that the "flame streak" contains very visible blue segments when only using neat $\mathrm{BD}$ (B100). This is mainly owed to the fact that a BDF has an oxygenated compound containing two oxygen atoms. The blue characteristic in the "flame streak" was visible only at the beginning and ending of the droplet burning process. "Flame streaks" formed with diesel and blended fuels did not contain very visible blue zones and this is mainly attributed to the fact that diesel has a higher tendency for soot formation yielding flames with strong soot luminosity that overcomes that of the blue flame [33]. These reported findings are in line with our observations that biodiesel-air flames tend to be characterized as having a thin blue zone flame just above the edge of the burner's mouth (Supplementary Data-1/Figure1). The burner employed in this study is similar as the one employed by K.O. Lee et al. for measuring soot volume fractions in methane flames [42]. A visual comparison between the K.O. Lee et al. methane flames and the neat CME/SME-air flames shows that a thin blue flame is strongly visible only in the BD flames. This correlates very well with the findings reported by Li et al. on the flame appearance of BD flames [33]. Furthermore, a visual comparison of the flame structure formed using CME/oxygen enriched-air and CME-air shows that the CME/oxygen flames have a much brighter yellow luminous zone (Supplementary Data-1/Figure1). However, the thin blue zone flame becomes 
less visible as the oxygen content is increased in the oxidizer stream. It is interesting to note that

393 the temperature profiles for the lower oxygen enriched air flames contain a concave up curve in

394 the upper part of the flame. The temperature profile for the CME-air flame shows the concave up 395 curve at approximately $\mathrm{HAB}=12 \mathrm{~mm}$; while for the $\mathrm{CME}-50 \% \mathrm{O}_{2}$ the effect is located at $\mathrm{HAB}$ $396=7.5 \mathrm{~mm}$. In the works of Hayashida et al. it is reported that such an effect is attributed to soot 397 deposition onto the surface of the thermocouple bead $[62,63]$. From the soot volume fraction 398 profiles in the present study, Fig. 2, for B100CME flames it can be observed that the location of 399 the concave up curve effect on the temperature profile correlates to the profile containing higher 400 soot volume fraction peaks. The temperature profile for the $\mathrm{CME}-80 \% \mathrm{O}_{2}$ flame does not contain 401 any concave up curve effect (figure 7). Attempts were made to measure the temperature of 402 flames formed using blended fuels (DB/No.2 Diesel) including B80CME/B50. During the 403 temperature measurements of the flame formed with the blended fuel it was observed that the 404 surface of the thermocouple bead became quickly covered with large fragments composed of 405 soot particulates as the soot field evolved in the direction of the flame's tip. The heavier 406 accumulation of soot on the surface of the thermocouple could result in inaccurate flame 407 temperature measurements. The temperature profiles for the blended flames exhibited a contrary 408 behavior to that of the neat BDF. The accumulation of black materials on the surface of the 409 thermocouple bead was significant for the blended fuel flames formed with air and as the initial 410 introduction of percentages of oxygen in the oxidizer stream took place. Specifically, the flame 411 temperature (axially along the centerline) increases from the edge of the fuel nozzle and 412 suddenly begins falling in the upper part of the flame as the soot field evolved.

4134.2 Soot volume fraction measurements in flames formed using CME blended with diesel fuel, 414 with air and oxygen-enriched air as oxidizers 

fuel. However, the utilization of raw BD in the existing compression ignition engines during

417 long-term tests does not follow up on trends observed for short-term testing. The best 418 application of these renewable fuels is by blending them with diesel fuel. A better understanding 419 of the characteristic soot propensity of BD and different biodiesel-diesel blends can provide 420 useful information in order to enhance the fundamental understanding of combustors running 421 with fuel blends with increased BD content. Various studies have been conducted with BD 422 blends in engines [64-67]. In the present work, the soot propensity of BD and different biodiesel423 diesel formed flames is studied. CME is chosen as the BDF to be blended with various 424 percentages (volumetric) of No. 2 diesel in this study. The blends consisted of B80 and B50. 425 For the $\mathrm{B} 80 \mathrm{CME}-21 \% \mathrm{O}_{2}, \mathrm{~B} 50 \mathrm{CME}-21 \% \mathrm{O}_{2} f_{\mathrm{v}}$ peak values of 4.32 and 4.68 were obtained (Fig. $4264 \mathrm{a}$ and $5 \mathrm{a}$ ), respectively. The $f_{\mathrm{v}}$ peak of 4.04 was measured for the $\mathrm{B} 100 \mathrm{CME}-21 \% \mathrm{O}_{2}$ flame (Fig. 427 2a). While the percentage of oxygen remained fixed in the oxidizer stream $\left(21 \% \mathrm{O}_{2}+79 \% \mathrm{~N}_{2}\right)$, 428 the increase of diesel percentage in the fuel blending mixture resulted in a high soot volume 429 fraction peak compared to the value obtained for the B100CME-air flame. This trend is in line 430 with the studies conducted using diesel engines, which show that while maintaining some 431 physical and chemical properties, as the blending percentage of BD in diesel fuel increases, the 432 emission of PM tends to decrease significantly [68-70 ]. It is well accepted in the literature that 433 the tendency of a fuel to form soot particles is mandated by the availability of incipient soot 434 nucleation during the combustion of a fuel. Soot inception and nucleation strongly depend on 435 the molecular structure of the fuel [71]. Diesel fuel is composed mainly of saturated 436 hydrocarbons (no double bonds) and aromatic compounds (ringed structures containing 6 437 carbons and alternating single and double bonds (Table 2). The complex molecular structure of 
438 the diesel fuel (saturated hydrocarbons and aromatics) allows for a unique reaction zone (high 439 rate of pyrolysis reactions) capable of producing more potential paths for soot nucleation and 440 formation [70]. The study of Chien et al. on the emission effects of biodiesel/Diesel blending in 441 a diesel engine showed that $\mathrm{BD}$ has much lower PAH content resulting in ultrafine PM in the 442 exhaust line [70].

443 The effect of oxygen content in the oxidizer stream on the soot formation was also studied in the 444 blended-fuel flames by varying the oxygen from air to 35\%, 50\% and 80\%. Figures 4 and 5 445 contain soot volume fraction profiles for B80CME and B50CME flames formed using various 446 oxygen contents in the oxidizer stream at various HAB. Figure 4 (a) $21 \%$, (b) $35 \%$, (c) $50 \%$, and 447 (d) $80 \%$ oxygen for the B80CME and Fig. 5 (a) $21 \%$, (b) $35 \%$, (c) $50 \%$, and (d) $80 \%$ oxygen for 448 the B50CME flames. For the B80CME flames the $f_{\mathrm{v}}$ peak values at $21 \%, 35 \%, 50 \%$ and $80 \%$ 449 oxygen are $4.32,6.35,7.41$ and $5.22 \mathrm{ppm}$. The change of oxygen content in the oxidizer stream 450 from $21 \%$ to $35 \%$ resulted in the increase of the $f_{\mathrm{v}}$ peak by approximately 47 percent. As the 451 oxygen content increased in the oxidizer stream from $35 \%$ to $50 \%$ oxygen the $f_{\mathrm{v}}$ peak increased 452 by approximately 17 percent. However, a further increase in the oxygen content in the oxidizer 453 stream (from $50 \%$ to $80 \%$ ) resulted in the decrease of $f_{\mathrm{v}}$ peak value by approximately 29 percent. 454 For the B50CME flames the $f_{\mathrm{v}}$ peak values at $21 \%, 35 \%, 50 \%$ and $80 \%$ oxygen are $4.68,7.87$, 4556.80 and 5.59 ppm, respectively. Figure 6(a to d) represents a summary on the effect of oxygen 456 concentration in the oxidizer stream on $f_{\mathrm{v}}$ peak values for tested neat $\mathrm{BD}(\mathrm{CME} / \mathrm{SME})$ and of the 457 blended fuel mixtures (CME/No. 2 Diesel) formed diffusion flames. It can be observed that the 458 variation of oxygen content in the oxidizer stream has two different and opposing effects on the 459 sooting tendency in the formed flames. Within a certain oxygen threshold the increase of oxygen 460 concentration can act as an inhibitor to soot by increasing the fuel pyrolysis and hence soot 
461 formation rates. In the contrary, a further increase of oxygen concentration in the oxidizer stream

462 (above a certain oxygen threshold) significantly compresses the flame volume, increases the

463 flame temperature thus increasing the particle oxidation rate and hence acting as soot suppressor.

464 This effect is very visible from our summary profiles of soot peaks (Fig. 6) and flame measured

465 temperatures at various oxygen contents in the oxidizer stream (Fig. 7).

$466 \quad 4.3$ Total Soot

467

Total soot content within a flame was estimated by integrating the $f_{\mathrm{v}}$ field distribution in

468 the radial and axial direction over the entire flame volume as sugusted by Zelepouga et al. [41].

469 Results are shown in Table 3. By inspecting Table 3, it becomes evident that the increase of No.

4702 diesel fuel content in the fuel mixtures causes an increase in the overall soot concentration

471 within the flame for all the tested oxygen contents. The integration scheme to obtain the total

472 soot content on a mass basis is defined as in equation (3) and employed by Zelepouga et al. in

473 coflow laminar diffusion flames of methane with oxygen and oxygen-enriched air [41]. The total

474 soot content of the flame (by mass) was calculated based on the results from the integration of

475 the $f v$ distribution and by selecting an average density for the solid carbonaceous materials within

476 the flame. In the literature the density values of the carbon materials generally ranges from 1.74

477 to $1.84 \mathrm{~g} / \mathrm{cm}^{3}[72]$.

$$
F_{V}=\rho_{s} \int_{0}^{H_{f}} \int_{0}^{R} f_{(r, z)} 2 \pi r d r d z
$$

478 Where $\rho_{\mathrm{s}}$ is the density for carbon material, $\mathrm{H}_{f}$ is the flame height and $\mathrm{R}$ is the radius of the

479 flame. Although the thermal and dilution effects are inevitably introduced to the tested flames 480 by altering the oxygen content in the oxidizer flow, B100CME and B100SME showed indistinct 481 behaviors regarding the total soot produced by flames of similar conditions when compared with 482 each other. 
483 On the other hand, for B80CME fuel, it was observed that the utilization of oxygen-enhanced air 484 as oxidizer has a soot enhancing effect as judged by the total soot load of the flame, only when 485 the oxygen content is increased from $21 \%$ to $35 \%$. Conversely, a further oxygen increase in the 486 oxidizer stream (50\% and $80 \%$ ) lead to significantly lower soot loads. Generally, the behavior 487 observed for the total soot content of B80CME flames closely follows the previously described 488 trend for peak $f_{\mathrm{v}}$ values. For B50CME flames operating at oxygen contents (21\% to $50 \%$ ) does 489 not show a dominant soot suppressing or enhancing effect. Moreover, for all the fuels, the $80 \%$ 490 oxygen flames were observed to produce significantly less soot than their counterparts operating 491 with air. The reduction for B100CME and B100SME was calculated to be $78 \%$ and $75 \%$ 492 respectively, while for the biodiesel-diesel blends; B50CME and B80CME, the reduction was 493 approximately $48 \%$ and $72 \%$, respectively. The lower sooting tendency of B100CME and 494 B100SME when compared to the biodiesel-diesel blends (B50CME, and B80CME) is most 495 likely resulting from the lower concentration of soot precursors in the early stages of the flame 496 (as shown in $f_{\mathrm{v}}$ profiles).

497 Moreover, we hypothesize that the reduction of the sooting tendency for B100CME and 498 B100SME compared to their blends is due to the increased concentration of $\mathrm{O} / \mathrm{C}$ atomic ratio 499 that occurs when forming the flames with a BDF. Oxygenated fuels tend to produce elevated CO 500 concentrations resulting in less carbon available to form particulate precursors. While the CO 501 formation cannot entirely account for the reductions in soot observed for B100SME and 502 B100CME, the differences in the molecular structure of these oxygenated fuels compared to 503 traditional No.2 diesel can partly explain the differences in the PM emissions (Tables 1 and 2). 
precisely corrected. However, the method is considered an excellent tool as it provides a relative comparison of the soot propensity between flames formed by varying different parameters within a single set of experiments. The first uncertainty that could occur in our calculations of soot 509 volume fractions could be due to the accuracy of the values of the assumed constants employed. 510 For instance, in our data analysis of the soot measurements we use an extinction coefficient with 511 a value of 4.9 that corresponds to the refraction index $m=1.57-0.56 \mathrm{i}$. This value has been 512 widely attributed to the work of Dalzell and Sarofim [48] and has been extensively employed in 513 soot-studies including in the measurements of soot volume fractions in methane-air and in 514 methane/oxygen and in oxygen enriched-air flames [73, 41, 42]. The extinction coefficient 515 constant $k_{\text {ext }}$ is obtained from refractive index of soot. The refractive index is defined as the ratio 516 of the refractive index of the particle to the refractive index of the medium. The work of Smyth 517 and Shaddix provides an excellent discussion on the history of the various values of refractive 518 indices of soot used for data analysis in flames. In that work it was concluded that errors can be 519 attributed to the degree to which scattering affects extinction measurements and its possible 520 variation within a flame [74]. Although, some investigators in soot related studies have reported 521 that refractive indices are independent of fuel [75], others, however, have proposed that a 522 refractive index can be a function of flame position and $\mathrm{C} / \mathrm{O}$ ratio [46, 47, 76]. 523 Charalampopoulos suggested that using a constant refractive index value over an entire flame 524 region (where significant variations of soot fields are present) can cause errors on the number 525 densities and soot particle size determinations of as much as $25 \%$ and $15 \%$, respectively [76]. 526 Another uncertainty could be due to the accuracy of the value of the density used for calculating 527 the total soot in the flames. In the literature the density values of carbon material generally range 528 from 1.74 to $2.0 \mathrm{~g} / \mathrm{cm}^{3}$ [41]. We employed a value of $1.8 \mathrm{~g} / \mathrm{cm}^{3}$. This value was used by K.O. 
Lee et al. in nonpremixed methane oxygen enhanced-air flames [42]. A not precise determination of the adequate number of soot volume fraction profiles necessary to capture the soot peak could also result in some uncertainties of the total amount of soot. Therefore, greater

532 care was devoted to obtain an appropriated number of soot volume fraction profiles within a 533 flame to most accurately obtain the total amount of soot produced. For instance, we obtained 534 thirteen soot volume fraction profiles in a CME-air flame within a distance of $15 \mathrm{~mm}$. The 535 additional profiles are not presented in the plots for clarity, but the results are presented in the 536 Table 3.

\section{5. Conclusions}

538 Soot formation in flames formed using various gaseous/hydrocarbon fuels in laboratory scale 539 counter-flow and coflow flames have been extensively studied and documented in the literature.

540 In those studies several parameters have been tested aiming at inhibiting or suppressing soot 541 formation in flames. More recently the introduction of oxygen enriched-air in the oxidizer stream 542 for studying soot formation in such flames has also been studied. In contrast, the literature 543 contains very limited information on the formation of carbon particulates from flames formed 544 using pre-vaporized fatty acid methyl esters (FAMEs). BD or FAMEs are considered a clean, 545 biodegradable and renewable fuel that has the potential to significantly interrupt the dependence 546 on petroleum-based fuels. However, given the importance and the significant impact that this 547 fuel contains; the understanding of soot formation in flames has received little attention, not to 548 mention the effect on soot formation that can result by fuel blending (FAMEs/diesel) and the

549 increase of oxygen content in the oxidizer stream in formed flames. In this present work soot 550 formation is experimentally investigated in laminar jet, non-premixed coflow flames formed 551 using BDF from canola and soybean oils. The laser extinction/scattering technique is employed. 
552 The effect of blending (CME blended with No.2 diesel: B80CME and B50CME) and the

553 variation of the percent of oxygen content in the oxidizer stream $(21 \%-80 \%)$ on soot formation

554 was investigated. It was found that the initial increase of oxygen content in the oxygen/nitrogen

555 mixture formed flames promotes soot formation; however, a further increase of oxygen content

556 suppresses soot formation in the tested flames. Furthermore, the increase of oxygen content in

557 the oxidizer stream compresses the flame volume and considerably stabilizes a flame formed

558 using neat BD and blended with ULSD (No. 2 diesel). It was found that the total soot for the neat

559 BD flames (B100CME and B100SME) does not significantly vary compared to the other

560 parameters such as the variation of oxygen content in the oxidizer stream and fuel blending. The

561 flame temperature variations between the B100CME and B100SME are not very significant and

562 may explain the similarity in the soot tendency between these two fuels. Soot inception can also

563 be affected by a mechanism other than flame temperature such as fuel chemistry. We

564 hypothesize that this effect could be due to the similarity of the five major methyl ester

565 compositions present in the fuels. This work also reveals that the $f \mathrm{v}$ peak values tend to be

566 significantly higher in flames formed using CME/SME compared to a gaseous/hydrocarbon fuel.

567 For instance, the measured $f \mathrm{v}$ peak value for a base B100CME-air flame is approximately 11

568 times higher than the $f v$ peak reported in the literature (by Lee O-K et al.) in a methane-air flame.

569 The exact same burner configuration was used in these two studies. It is observed that by

570 increasing the oxygen content in the B100CME flame from $21 \%$ to $35 \%$ the value of the $f_{\mathrm{v}}$ peak

571 increases by approximately 47 percent. The increase in oxygen content in the tested flames

572 increases the temperature of the flame resulting in the increase of fuel pyrolysis rates,

573 significantly augmenting the formation of soot precursors in the lower part of the flame, which in

574 turn leads to a higher density of soot particles in the upper part of the flame. A further increase 
575 of oxygen content suppressed soot formation and reduced $f_{\mathrm{v}}$ peak values. That is, the $f_{\mathrm{v}}$ peak

576 values for B100CME for 35\%, 50\% and 80\% oxygen were measured as $6.50 \mathrm{ppm}, 5.82 \mathrm{ppm}$ and

$5773.22 \mathrm{ppm}$, respectively. A similar trend is observed for the other tested BDF. However, a further

578 augmented oxygen concentration also restricts the reaction zone to the lower part of the flame,

579 limiting the residence time for soot agglomeration and consequently limiting the total and peak

580 soot volume fractions within the flame. The effect of fuel blending using CME with various

581 percentages (volumetric) of No. 2 diesel showed that the total soot increased. The values of the

582 total soot concentrations for some of these tested flames are nearly doubled as the oxygen

583 content in the oxidizer stream is increased. Diesel fuel has complex molecular structure

584 (saturated hydrocarbons and aromatics) that can result in a high rate of pyrolysis reactions

585 capable of producing more potential paths for soot inception and formation. Our results show

586 that indeed the soot production significantly enhances as the blending percentage of CME with

587 No. 2 diesel is increased.

588 Temperature measurements were also conducted along the symmetry axis of selected flames at 589 different heights using K-type fast-response thermocouple. Comparing the soot volume fraction 590 with the measured local flame temperatures at each flame position reveals that the higher the 591 temperatures, the higher the oxidation rate of the soot particles, and hence the lower the $f_{\mathrm{v}}$ peak 592 values.

\section{Acknowledgments}

594 The support of this work by the National Science Foundation through the research grant CBET-

5951067395 is gratefully acknowledged. The authors would like to thank Dr. Alexei Saveliev from 596 NCSU for his input and helpful discussions. 
[1] ASME D6751-12. Standard Specification for Biodiesel Fuel Blend Stock 2014:1-10.

[2] U.S. Energy Information Administration, Monthly Energy Review DOE/EIA0035(2013/04), April 2013.

[3] Department of Energy/Energy Administration, Annual Energy Outlook DOE/EIA-0383, February 2007.

[4] Xue J, Grift TE, Hansen AC. Effect of biodiesel on engine performances and emissions. Renew Sustain Energy Rev 2011;15:1098-116.

[5] Demirbas A. Importance of biodiesel as transportation fuel. Energy Policy 2007;35:466170.

[6] Song J, Alam M, Boehman AL, and Kim U. Examination of the oxidation behavior of biodiesel soot. Combust Flame 2006; 146;589-604.

[7] Szybist JP, Song J, Alam M, Boehman AL. Biodiesel combustion, emissions and emission control. Fuel Process Technol 2007;88:679-91.

[8] Nguyen T, Do L, Sabatini DA. Biodiesel production via peanut oil extraction using dieselbased reverse-micellar microemulsions. Fuel 2010;89:2285-91.

[9] Patil PD, Deng S. Optimization of biodiesel production from edible and non-edible vegetable oils. Fuel 2009;88:1302-6.

[10] Thanh LT, Okitsu K, Sadanaga Y, Takenaka N, Maeda Y, Bandow H. A two-step continuous ultrasound assisted production of biodiesel fuel from waste cooking oils: a practical and economical approach to produce high quality biodiesel fuel. Bioresour Technol 2010;101:5394-401.

[11] Alptekin E, Canakci M. Characterization of the key fuel properties of methyl ester-diesel fuel blends. Fuel 2009;88:75-80.

[12] DeOliveira E, Quirino RL, Suarez PAZ, Prado AGS. Heats of combustion of biofuels obtained by pyrolysis and by transesterification and of biofuel/diesel blends. Thermochim Acta 2006;450:87-90.

[13] Glaude P-A, Fournet R, Bounaceur R, Molière M. Adiabatic flame temperature from biofuels and fossil fuels and derived effect on NOx emissions. Fuel Process Technol 2010;91:229-35.

[14] de Souza GR, dos Santos AM, Ferreira SL, Ribeiro Martins KC, Módolo DL. Evaluation of the performance of biodiesel from waste vegetable oil in a flame tube furnace. Appl Therm Eng 2009;29:2562-6.

[15] Guan G, Kusakabe K, Sakurai N, Moriyama K. Transesterification of vegetable oil to biodiesel fuel using acid catalysts in the presence of dimethyl ether. Fuel 2009;88:81-6.

[16] Zhang J, Chen S, Yang R, Yan Y. Biodiesel production from vegetable oil using heterogenous acid and alkali catalyst. Fuel 2010;89:2939-44.

[17] Demirbas A. Potential applications of renewable energy sources, biomass combustion problems in boiler power systems and combustion related environmental issues. Prog Energy Combust Sci 2005;31:171-192.

[18] Lapuerta M, Armas O, Rodriguez-Fernandez J. Effect of biodiesel fuels on diesel engine emissions. Prog Energy Combust Sci 2008;34:198-223.

[19] Moser BR. Influence of blending canola, palm, soybean, and sunflower oil methyl esters on fuel properties of biodiesel. Energy Fuels 2008; 22(6): 4301-4306. 
[20] Canola and Rapeseed: Production, Processing, Food Quality, and Nutrition. ThiyamHolländer U, Eskin MNA, Matthäus B. CRC Press. 2012.

[21] Coleman B. Canola: an excellent feedstock for biodiesel. Biodiesel Magazine 2006;1:256.

[22] Canola Council of Canada report. Overview of Canada's canola industry. 2005 /www.canola-council.org/ind_overview. htmlS. Accessed on January 3, 2008.

[23] Cao P, Dube MA, Tremblay AY. High-purity fatty acid methyl ester production from canola, soybean, palm, and yellow grease lipids by means of a membrane reactor. Biomass Bioenergy 2008; 32:1028-1036.

[24] U.S. Department of Energy. Monthly Biodiesel Production Report. June 2014. Washington, DC 20585.

[25] Canakci M, Van Gerpen JH. Comparison of engine performance and emissions for petroleum diesel fuel, yellow grease biodiesel, and soybean oil biodiesel. Trans ASAE 2003;46:937-44.

[26] Jung H, Kittelson DB, Zachariah MR. Characteristics of SME biodiesel-fueled diesel particle emissions and the kinetics of oxidation. Environ Sci Technol 2006;40:4949-55.

[27] Vander Wal RL, Strzelec A, Toops TJ, Stuart Daw C, Genzale CL. Forensics of soot: C5related nanostructure as a diagnostic of in-cylinder chemistry. Fuel 2013;113:522-6.

[28] Feng Q, Jalali A, Fincham AM, Wang YL, Tsotsis TT, Egolfopoulos FN. Soot formation in flames of model biodiesel fuels. Combust Flame 2012;159:1876-93.

[29] Tran MK, Dunn-Rankin D, Pham TK. Characterizing sooting propensity in biofuel-diesel flames. Combust Flame 2012;159:2181-91.

[30] Love ND, Goepfert BT, Parthasarathy RN, Gollahalli SR. Comparison of Soot Volume Fraction, Temperature, and Radiation in Petroleum Diesel and Biodiesel Flames. AIAA Aerosp Sci Meet Exhib Reno, Nevada 2008:January 7-10.

[31] Jha SK, Fernando S., To SDF. Flame temperature analysis of biodiesel blends and components. Fuel 2008; 87: 1982-1988.

[32] Merchan-Merchan W, Sanmiguel SG, McCollam S. Analysis of soot particles derived from biodiesels and diesel fuel air-flames. Fuel 2012;102:525-35.

[33] Li TX, Zhu DL, Akafuah NK, Saito K, Law CK. Synthesis, droplet combustion, and sooting characteristics of biodiesel produced from waste vegetable oils. Proc Combust Inst 2011; 33:2039-2046.

[34] Charles E. Baukal Jr. Oxygen-enhanced combustion. 2nd ed. Boca Raton, FL: CRC Press; 2013.

[35] Santoro RJ, Yeh TT, Horvath JJ, Semerjian HG. The Transport and Growth of Soot Particles in Laminar Diffusion Flames. Combust Sci Technol 1987;53:89-115.

[36] Lin R, Zhu Y, Tavlarides LL. Mechanism and kinetics of thermal decomposition of biodiesel fuel. Fuel 2013;106:593-604.

[37] Basha SA, Gopal KR, Jebaraj S. A review on biodiesel production, combustion, emissions and performance. Renew Sustain Energy Rev 2009;13:1628-34.

[38] Kent JH, Wagner HG. Who do Diffusion flames Emit smoke. Combust Sci Technol 1984;41:245-69.

[39] Saito K, Williams F a., Gordon a. S. Effects of Oxygen on Soot Formation in Methane Diffusion Flames. Combust Sci Technol 1986;47:117-38. 
[40] Beltrame A, Porshnev P, Merchan-Merchan W, Saveliev A, Fridman A, Kennedy L., et al. Soot and NO formation in methane-oxygen enriched diffusion flames. Combust Flame 2001;124:295-310.

[41] Zelepouga SA, Saveliev A V, Kennedy LA, Fridman AA. Relative effect of acetylene and PAHs addition on soot formation in laminar diffusion flames of methane with oxygen and oxygen-enriched air. Combust Flame 2000;122:76-89.

[42] Lee K-O, Megaridis CM, Zelepouga SA, Saveliev AV., Kennedy LA, Charon O, et al. Soot formation effects of oxygen concentration in the oxidizer stream of laminar coannular nonpremixed methane/air flames. Combust Flame 2000;121:323-33.

[43] Henning B. Soot Formation in Combustion. Springer Berlin Heidelberg; 1994.

[44] Dalzell HW, Saforim AF. Optical Constants of Soot and their Application to Heat-Flux Calculations. J Heat Transf 1969;91:100-4.

[45] Shaddix KC, Smyth CR. The Elusive History of $m=1.57-0.56 \mathrm{i}$ for the Refractive Index of Soot 1996;320:314-20.

[46] Mullins J, Williams A. The optical properties of soot: a comparison between experimental and theoretical values. Fuel 1987;66:277-80.

[47] Alfè M, Apicella B, Barbella R, Rouzaud J-N, Tregrossi A, Ciajolo A. Structure-property relationship in nanostructures of young and mature soot in premixed flames. Proc Combust Inst 2009;32:697-704.

[48] Dalzell HW, Saforim AF. Optical constants of soot and their application to heat-flux calculations. J Heat Transf 1969;91:100-4.

[49] Santoro RJ. Soot particle measurements in diffusion flames. Combust. Flame 1983;51: 203-218.

[50] Dasch CJ. One-dimensional tomography: a comparison of Abel, onion-peeling, and filtered backprojection methods. Appl. Opt. 1992; 31:1146-1152.

[51] Saito K, Williams F a., Gordon a. S. Effects of Oxygen on Soot Formation in Methane Diffusion Flames. Combust Sci Technol 1986;47:117-38.

[52] DU DX, Axelbaum RL, Law CL. Soot formation in strained diffusion flames with gaseous additives. Combusiton and Flame 1995;102:11-20.

[53] Gomez A, Littman MG, Glassman I. Comparative study of soot formation on the centerline of axisymmetric laminar diffusion flames: fuel and temperature effects. Combust Flame 1987;70:225-241.

[54] Knothe G. Dependence of biodiesel fuel properties on the structure of fatty acid alkyl esters. Fuel Processing Technology 2005; 86:1059-1070.

[55] Kitamura T, Ito T, Senda J, Fujimoto H. Detailed chemical kinetic modeling of diesel spray combustion with oxygenated fuels. SAE Tech Pap 2001;01:1262.

[56] Tran MK, Dunn-Rankin D, Pham TK. Characterizing sooting propensity in biofuel-diesel flames. Combust Flame 2012;159:2181-91.

[57] McEnally CS and Pfefferle LD. Sooting tendencies of oxygenated hydrocarbons in laboratory-scale flames. Environ. Sci. Technol. 2011; 45:2498-2503.

[58] Hindasageri V, Vedula RP, Prabhu SV. Thermocouple error correction for measuring the flame temperature with determination of emissivity and heat transfer coefficient. Review of Scientific Instruments 2013; 84:024902-11.

[59] Roper FG. The prediction of laminar jet diffusion flame sizes: Part I, theoretical model. Combust. Flame 1977; 29:219-226. 
[60] Sugiyama G. Nonluminous diffusion flame of diluted acetylene in oxygen-enriched air. Symp Combust 1994;25:601-8.

[61] Du J, Axelbaum RL. The Effect of Flame Structure on Soot-Particle Inception in Diffusion Flames. Combust Flame 1995;100:367-75.

[62] Hayashida K, Nagaoka S, Ishitani H. Growth and oxidation of graphitic crystallites in soot particles within a laminar diffusion flame. Fuel 2014;128:148-54.

[63] Hayashida K, Mogi T, Amagai K, Arai M. Growth characteristics of polycyclic aromatic hydrocarbons in dimethyl ether diffusion flame. Fuel 2011;90:493-8.

[64] Agarwal AK. Biofuels (alcohols and biodiesel) applications as fuels for internal combustion engines. Prog Energy Combust Sci 2007;33:233-71.

[65] Agarwal AK. Biodiesel development and characterization for use as a fuel in compression ignition engines. Trans ASME 2014;123.

[66] Tang H, Salley S, Simonng K. Fuel properties and precipitate formation at low temperature in soy-, cottonseed-, and poultry fat-based biodiesel blends. Fuel 2008;87:3006-17.

[67] Lin Y, Lee W, Wu T, Wang C. Comparison of PAH and regulated harmful matter emissions from biodiesel blends and paraffinic fuel blends on engine accumulated mileage test. Fuel 2006;85:2516-23.

[68] Wang WG, Lyons DW, Clark NN, Gautam M, Norton PM. Emissions from Nine Heavy Trucks Fueled by Diesel and Biodiesel Blend without Engine Modification. Environ Sci Technol 2000;34:933-9.

[69] McCormick RL, Graboski MS, Alleman TL, Herring AM, Tyson KS. Impact of Biodiesel Source Material and Chemical Structure on Emissions of Criteria Pollutants from a Heavy-Duty Engine. Environ Sci Technol 2001;35:1742-7.

[70] Chien S, Huang Y, Chuang S, Yang H. Effects of Biodiesel Blending on Particulate and Polycyclic Aromatic Hydrocarbon Emissions in Nano / Ultrafine / Fine / Coarse Ranges from Diesel Engine. Aerosol andAir Qual Res 2009;9:18-31.

[71] Bryce DJ, Ladommatos N, Zhao H. Quantitative Investigation of Soot Distribution by Laser-Induced Incandescence. Appl Opt 2000;39:5012.

[72] Lee K-O, Choi MY. Investigation of Sooting in Microgravity Droplet Combustion. Symp Combust 1996;25:1243-9.

[73] Shaddix CR, Harrington JE, Smyth KC. Quantitative measurements of enhanced soot production in a flickering methane/air diffusion flame. Combust Flame 1994;99:723-732.

[74] Smyth KC and Shaddix CR. The elusive history of $m=1.57-0.56 \mathrm{i}$ for refractive index of soot. Combust. Flame 1996;107:314-320.

[75] Chan ML, Moody KN, Mullins JR, Williams A. Low-temperature oxidation of soot. Fuel 1987;66:277-280.

[76] Charalampopoulos TT and Felske JD. Refractive indices of soot particles deduced from in-situ laser light scattering measurements. Combust Flame 1987;68:283-294. 


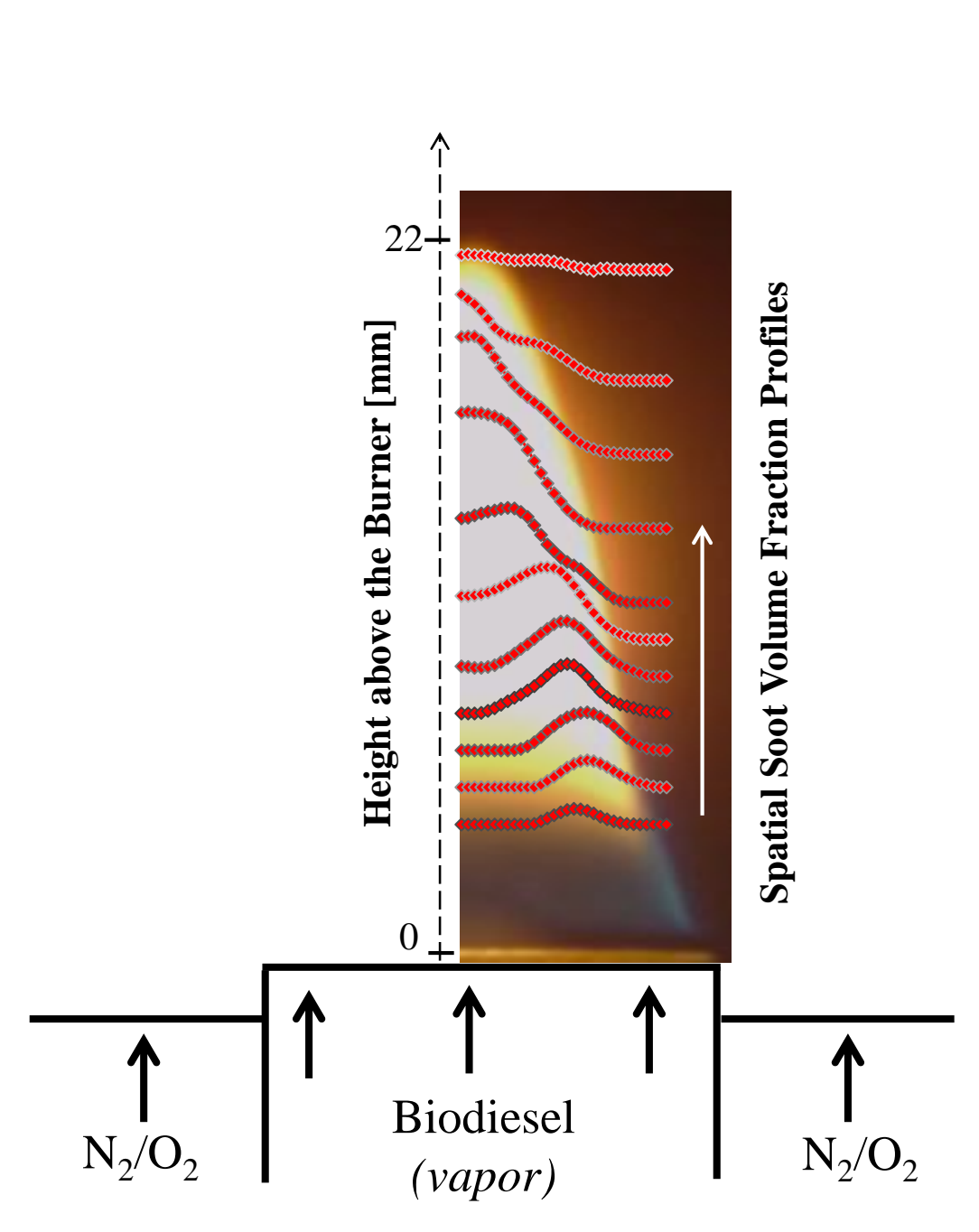

Graphical Abstrac 


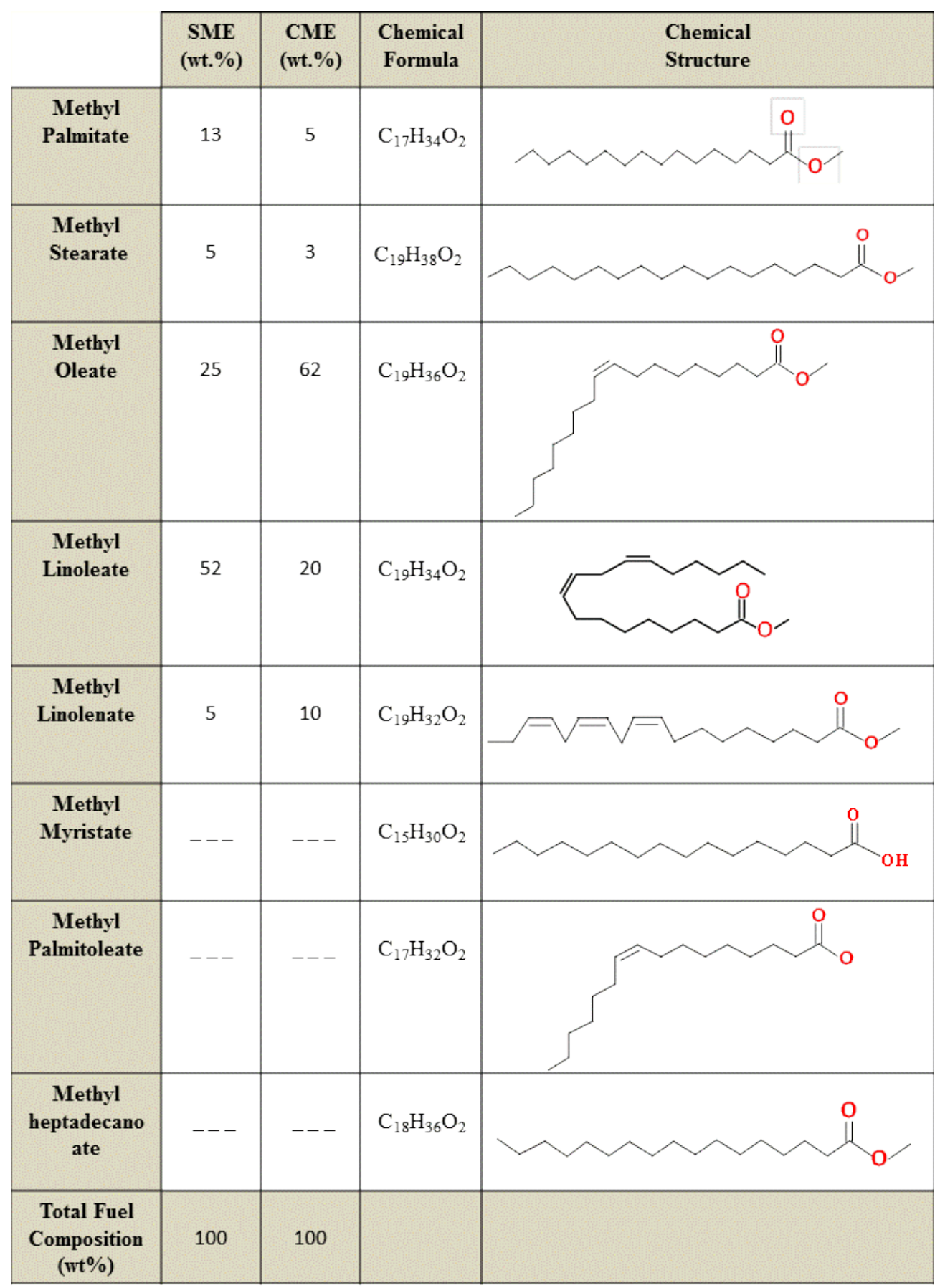

Table 1. Physical Properties and Chemical Structure of Constituent Fatty Acid Methyl Esters Present in Studied Biodiesel Fuel 
Your MS PowerPoint document "Table 3R.pptx" cannot be opened and processed. Please see the common list of problems, and suggested resolutions below.

\section{Embedded Macros}

Your submission should not contain macros. If they do, an alert box may appear when you open your document (this alert box prevents EM from automatically converting your PowerPoint document into the PDF that Editors and Reviewers will use). You must adjust your PowerPoint document to remove these macros.

PowerPoint 2002/PowerPoint XP files

At the present time, EM supports PowerPoint files in PowerPoint 2000 and earlier formats. If you are using a more recent version of MS PowerPoint, try saving your PowerPoint document in a format compatible with PowerPoint 2000, and resubmit to EM.

Other Problems

If you are able to get your PowerPoint document to open with no alert boxes appearing, and you have submitted it in PowerPoint 2000 (or earlier) format, and you still see an error indication in your PDF file (where your PowerPoint document should be appearing). please contact the journal via the 'Contact Us' button on the Navigation Bar.'

You will need to reformat your PowerPoint document, and then re-submit it. 


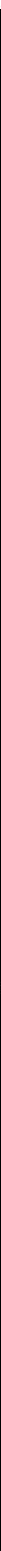

Figure 1. Schematic of the experimental setup for obtaining soot volume fraction profiles in coflow diffusion flames formed using biodiesel and biodiesel/diesel blends (a). Detailed view of the coflow burner (b); c) representative photographs of coflow flames formed using B100CME at various oxygen content in the oxidizer stream from $21 \%$ to $80 \%$; d) flames formed at B80CME, B50CME and B100SME. The blended fuel mixture was formed using the biodiesel from canola and soybean oils with No. 2 Diesel (volume basis). 

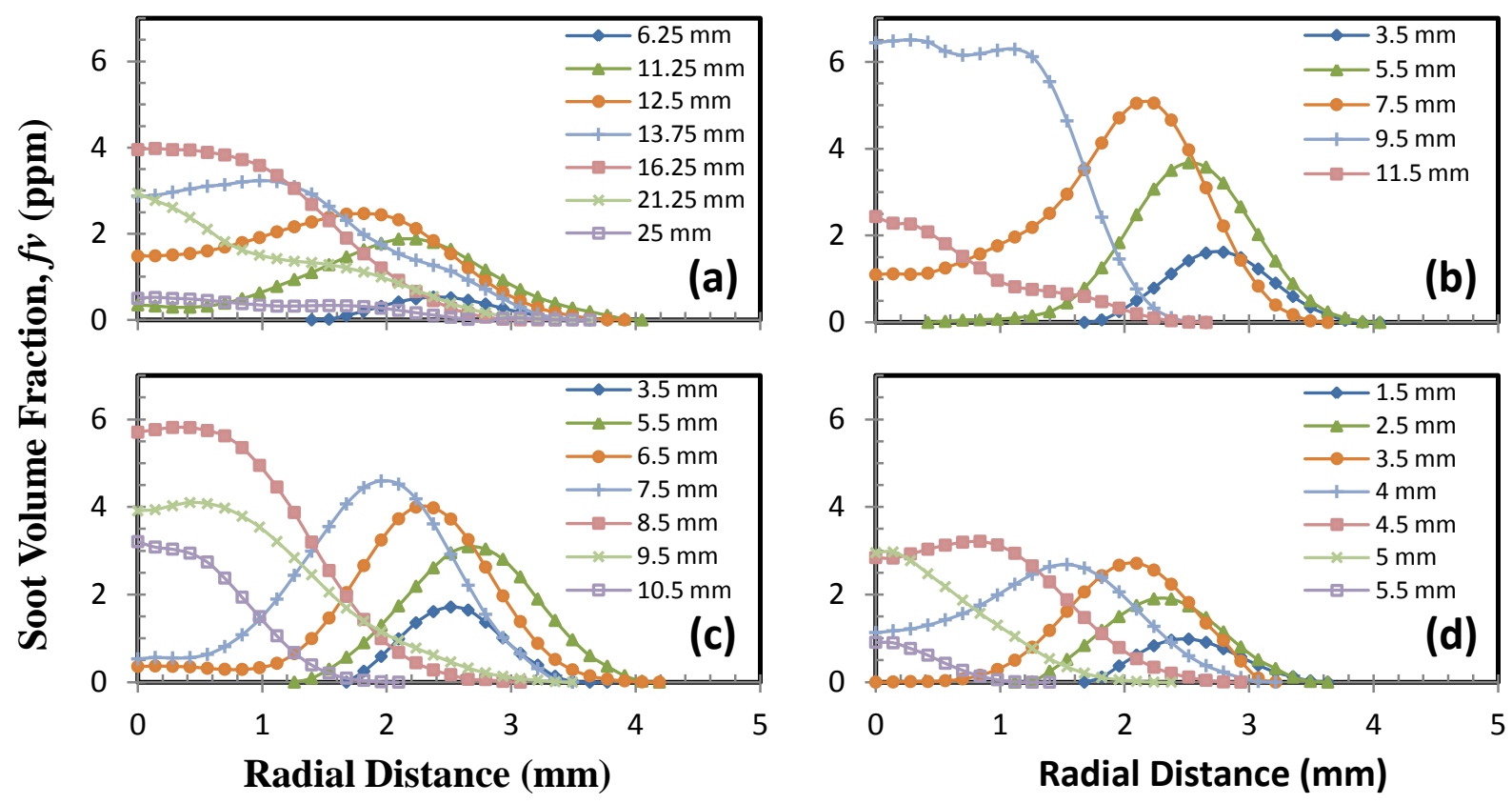

Figure 2. Spatial distribution of soot volume fraction for B100CME flames, operated at 4 oxygen concentrations in the oxidizer stream: (a) 21\%, (b) 35\%, (c) 50\%, (d) $80 \%$ at various heights above the burner (HAB). 

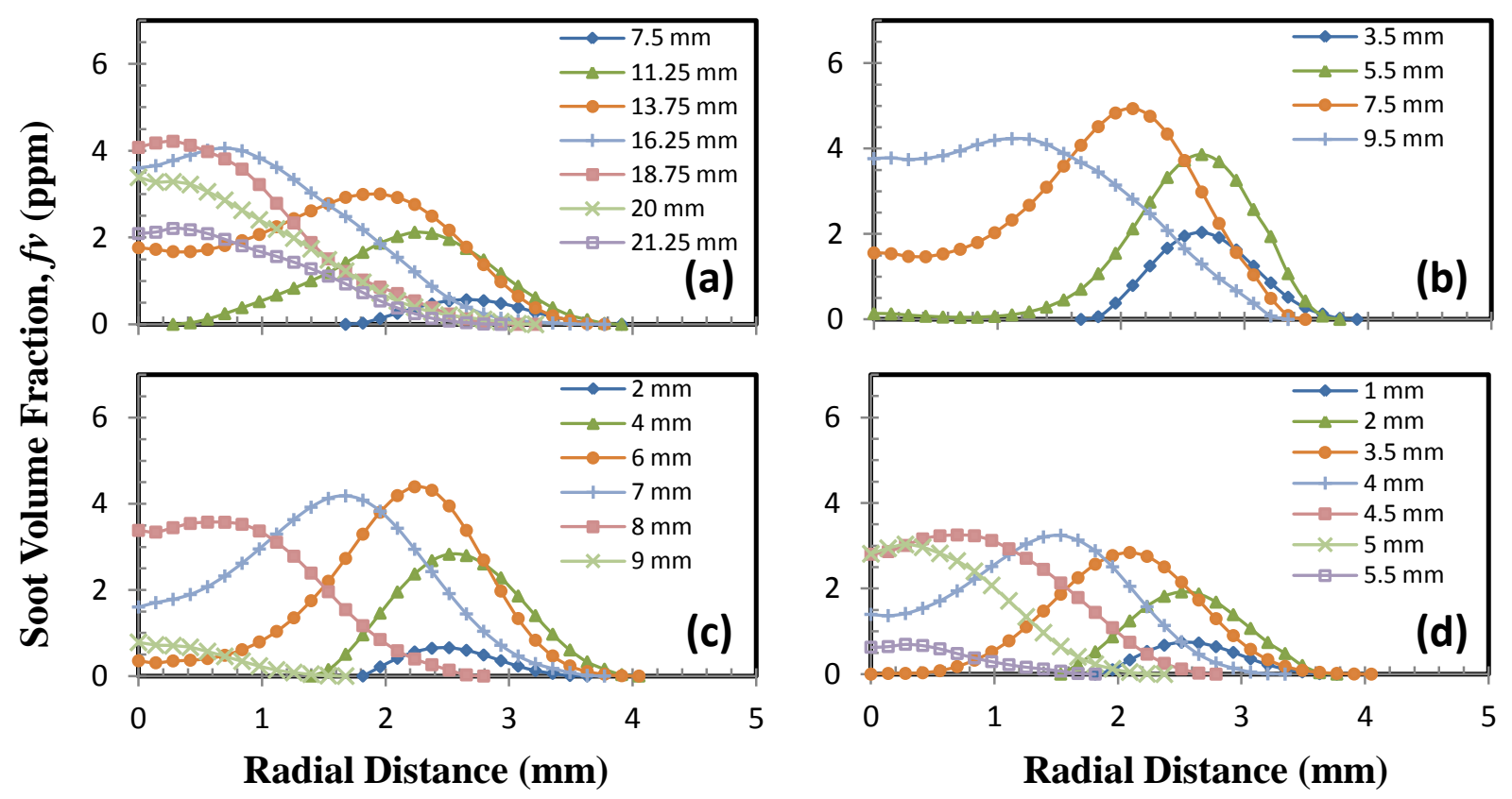

Figure 3. Spatial distribution of soot volume fraction for B100SME flames, operated at 4 oxygen concentrations in the oxidizer stream: (a) 21\%, (b) 35\%, (c) 50\%, (d) $80 \%$ at various $H A B$. 

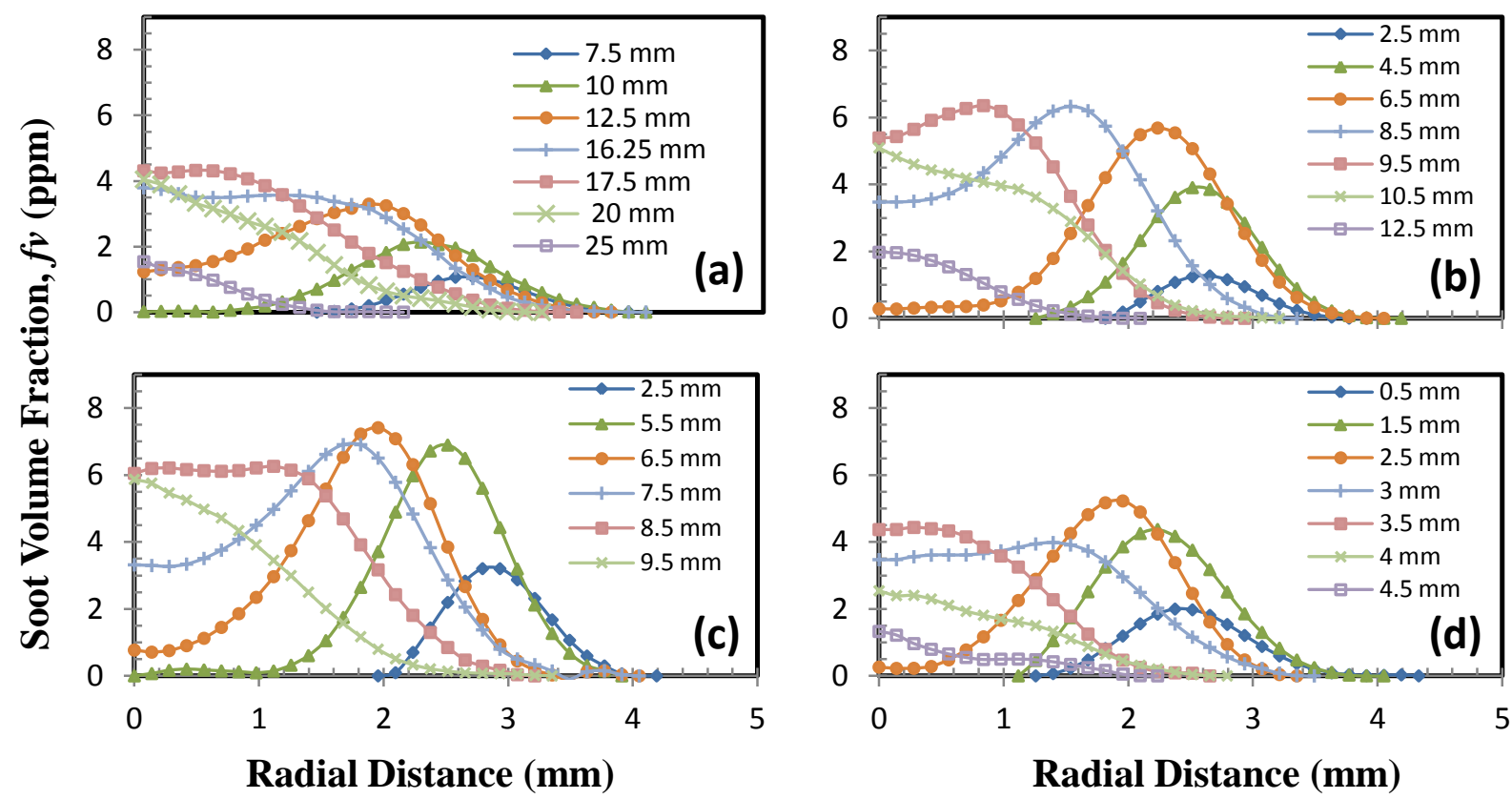

Figure 4. Spatial distribution of soot volume fraction for B80 CME flames, operated at 4 oxygen concentrations in the oxidizer stream: (a) 21\%, (b) 35\%, (c) 50\%, (d) $80 \%$ at various $H A B$. 

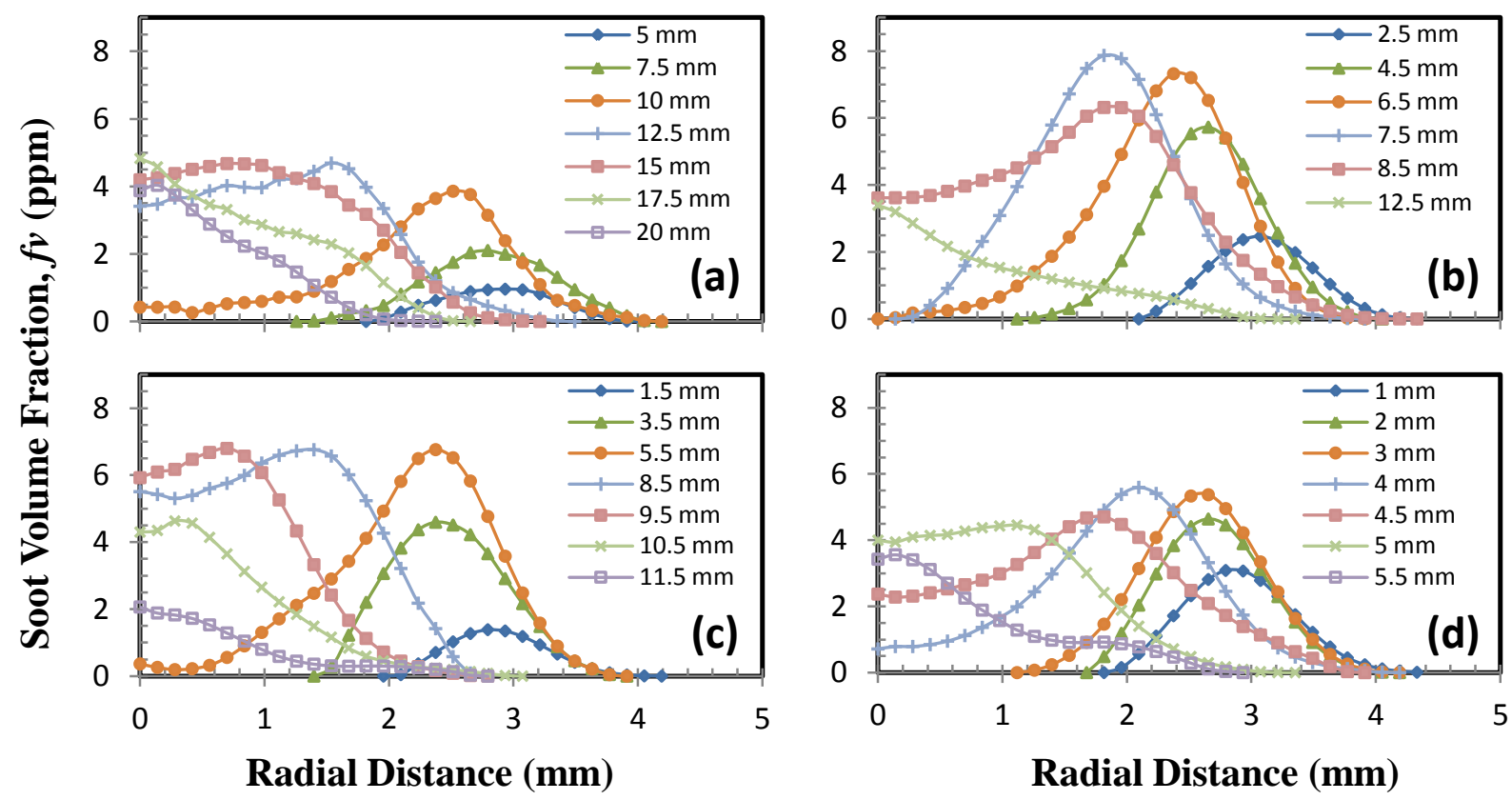

Figure 5. Spatial distribution of soot volume fraction for B50 CME flames, operated at 4 oxygen concentrations in the oxidizer stream: (a) 21\%, (b) 35\%, (c) 50\%, (d) $80 \%$ at various $H A B$. 

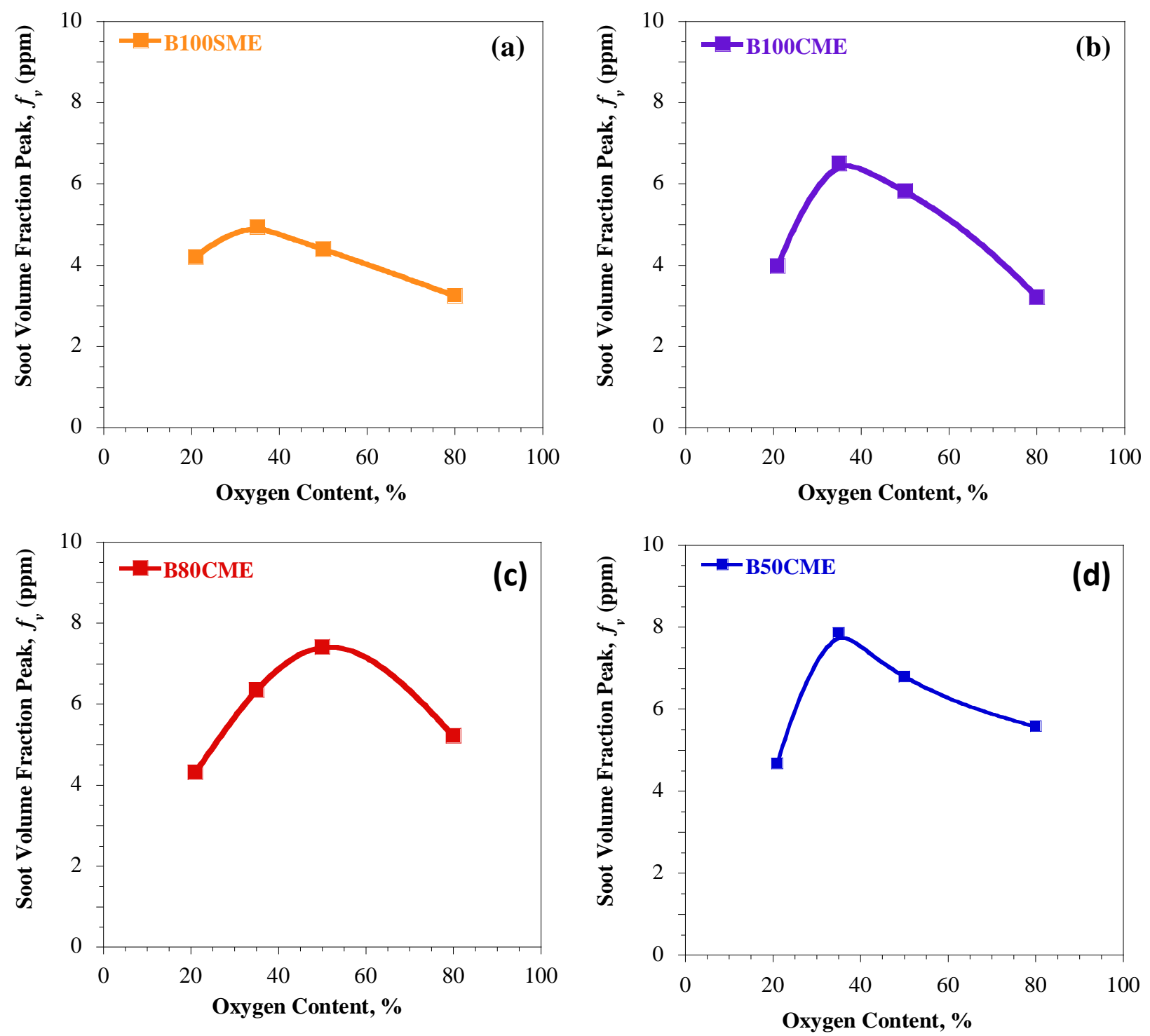

Figure 6. Summary of soot volume fraction peak values for (a to d) B100SME, B100CME, B80CME and B50CME formed flames, as a function of the oxygen content in the oxidizer stream. 

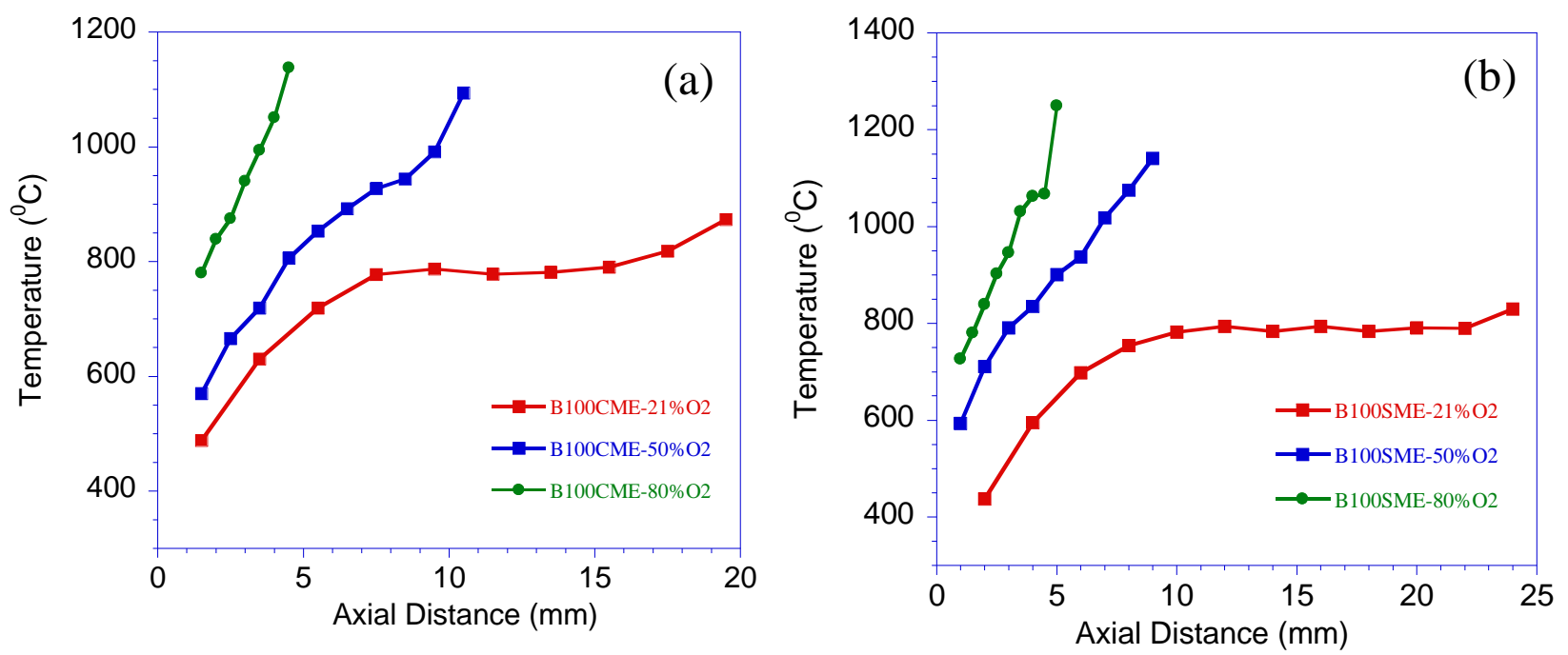

Figure 7. Measured temperature profiles along the centerline axial direction in flames; a) formed using B100CME and b) B100SME for various oxygen contents in the oxidizer stream. 